\title{
From Holism to Participation: Three Phases in Durkheim's Work
}

\author{
Bjørn Schiermer ${ }^{1}$ (1)
}

\begin{abstract}
The present paper seeks to read out important displacements regarding the understanding of the relation between the social and the individual in the course of Durkheim's oeuvre. First, I center on Durkheim's methodological program. I investigate how his insistence on the distinction between the individual and the social goes hand-in-hand with a repressive concept of the social centered on the concept of norms. I then, second, seek to contour an intermediary phase in Durkheim's work in which the coercive depiction of the social is complemented with a positive one; this phase then contains his ideas of "integration" and of a (positive) form of "attachment" to society. Third, I demonstrate how Durkheim in his late chief work, by opening up for forms of active collective participation, offers a corrective to the early holism and the idea of an overarching and decollectivized society. Fourth, to situate my interpretation of late Durkheim in a contemporary theoretical landscape, I compare my ideas to the approaches to late Durkheim found in, respectively, Randall Collins' work on Interaction Ritual Chains and in Jeffrey Alexander and collaborators' so-called Strong Program.
\end{abstract}

\section{Keywords}

Collectivity • Durkheim • Norm • Participation • Ritual • Structure

\footnotetext{
1 Correspondence to: Bjørn Schiermer, Department of Sociology and Human Geography, Det Samfunnsvitenskapelige Fakultet, Universitetet i Oslo, Harriet Holters hus Moltke Moesvei 31, Oslo 0317 Norway. Email: bjornsa@gmail.com ORCID: 0000-0002-8643-543X
}

To cite this article: Schiermer, B. (2019). From holism to participation: Three phases in Durkheim's work. İstanbul Üniversitesi Sosyoloji Dergisi, 39, 109-133. https://doi.org/10.26650/SJ.2019.39.1.0012 
Even though Durkheim insisted on the continuity and consistency of his life's work, there is no doubt that it contains important conceptual displacements and shifts; displacements which transcend mere changes to focus or interest and which entail fundamental shifts in sociological concerns and concepts centered on the very relation between the social and the individual. In this paper, I shall seek to highlight some of these shifts and critically read out their sociological-theoretical consequences.

In particular, I wish to show that Durkheim's late work - notably the descriptions of effervescent collectivity, the generalization of the concept of the sacred object, the emphasis placed on actual ritual participation- carries emphatic theoretical relocations, the scope of which transcends his own treatment or understanding of the issues at stake here. As I will try to show, taking these descriptions seriously not only entails a radical rupture with Durkheim's early work, but also with the very concept of society -in terms of an overarching normative structure- in favor of a contextual concept of collectivity. As I also intend to show, these developments in the late work, carry extensive empirical explanatory potential.

The paper is divided into three different scenarios or "phases". The first phase centers on The Rules of Sociological Method ([1895] 2013b). ${ }^{2}$ I seek to show how Durkheim, forced by his wish to demarcate an object for his new science of sociology, ends up over-emphasizing the distinction between the individual and the social. The emphasis placed upon this distinction goes hand in hand with a "coercive" concept of the social, which understands the social as a mere structure of decontextualized norms imposing themselves on isolated individuals. It thus, consequently, blends out the collective dimension.

Thereupon I turn to what I deem the second phase in Durkheim's work, stretching all the way from Suicide ([1897] 2002a) to his late lectures on morality ([1906] 1965a). Here I focus on his writings on "integration" and morality and his attempt to complement the early "coercive" concept of the social with a positive aspect of "attachment" to the group or to society. I seek to show, however, that he remains influenced by the holism of the early work in ways which block his attempts to reintegrate the individual and the social.

The Elementary Forms of Religious Life ([1912] 1995) stands at the center of analysis in the third phase of Durkheim's work. I investigate Durkheim's late descriptions of effervescence and of the "ritual" charging of the sacred object. I demonstrate how these passages offer a corrective to the early holism by opening up for active participation and production of the social. I show how these descriptions entail

2 In the following, to give the reader some temporal bearings, I have decided to list the year of original (French) publication or (if the year of publication differs decisively from the year it was first written down) of actual production [in brackets]. I quote from the English translations referenced in the bibliography. I have allowed myself to abbreviate recurring titles. 
an alternative concept of normativity which is inseparable from the positive sense of collective attachment. By reintegrating the normative and coercive component in the concrete collective context - by decisively entangling or mixing the negative and the positive components, as it were - these descriptions move beyond the repressive concept of the social of the early work and, ultimately, beyond the very dichotomy between actor and structure. Finally, I sketch the sociological and empirical potential of these conceptual developments in Durkheim's late work.

In a fourth section, I seek to contrast my interpretation of late Durkheim with other contemporary approaches. I compare my ideas as to the progressive tendencies in the late work - my interpretation of the Durkheimian sacred and the relation between myth and ritual, culture and collectivity, it implies- to similar attempts to revitalize the late Durkheim found in, respectively, Randall Collins' work on Interaction Ritual Chains and in Jeffrey Alexander and collaborators' so-called Strong Program.

Two clarifications need to be made before we start: first, on a terminological level, I seek to enforce a distinction between the concepts of sociality and collectivity. As already indicated, at least in early Durkheim, the concept of the social is essentially to be understood as a structure or system of norms or rules. Contrastingly, when I use the concept of collectivity, I mean to imply actual relations with other persons -present or "mediated", intimate or anonymous- as well as the (conscious or unconscious) sentiment of sharing something with these other persons. This distinction is not consistently carried through though; sometimes I use the concept of the social against Durkheim himself. I hope it is clear from the context when I have such intentions. Second, the reader should understand the idea of three "phases" in Durkheim's work as merely analytical or "ideal-typical". It would be more correct to speak about a gradual evolution and a change in the relative importance of different conceptions. The collective and active dimension is present in glimpses even in Durkheim's earliest work just as the coercive, external and "de-collectivized" understanding of the social remains with him to the end. ${ }^{3}$

\section{First Phase: Coercion}

As is well known, Durkheim strongly insists in Rules ([1895] 2013b, pp. 36-38) on the "externality" of the social fact. The social is to be engaged with the same positivist attitude as in the sciences of nature, and thus as decoupled from psychological or introspective interpretation as possible. The social is to be studied analogously to the objects of natural science, i.e. as "real" -observable-forces and causes. Nevertheless,

3 I will permit myself to overlook the earliest work of Durkheim, i.e. work from before Division ([1893] 2013a), both for reasons of space but also because I think Rules ([1895] 2013b) - which stands at the center of my analysis of the first phase - possesses a special status as the first elaborated and authoritative formulation of his ideas about the social and his sociological program. 
it is obvious that Durkheim's idea of "externality" has a psychological component. ${ }^{4}$ It is the sentiment or experience of suffering tangible negative sanction in one form or another which first of all defines the social fact:

[T]here are ways of acting, thinking and feeling which possess the remarkable property of existing outside the consciousness of the individual. Not only are these types of behavior and thinking external to the individual, but they are endued with a compelling and coercive power by virtue of which, whether he wishes it or not, they impose themselves upon him. Undoubtedly when I conform to them of my own free will, this coercion is not felt or felt hardly at all, since it is unnecessary. None the less, it is intrinsically a characteristic of these facts; the proof of this is that it asserts itself as soon as I try to resist ([1895] 2013b, p. 21).

The sentiment of "coercion" then stands as a proof of the externality of social facts. Externality in this sense means first of all the acting of "society" upon the individual "from without" in terms of a normative force acutely felt by the individual if or when he or she breaches a norm. Durkheim imagines a normative grid which predates and outlasts the singular individual and which is largely taken over from previous generations through implicit or explicit socialization, internalization and education. It follows from this line of thinking that this lasting and transcending normative structure cannot be explained on the basis of the active behavior of the individuals, but rather explains (central aspects of) thereof. This is Durkheim's methodological holism. Society exists sui generis. It is not reducible to its parts, but has a reality of its own which determines the parts. It thus constitutes a demarcated object for a new science: sociology.

Now, to make sure that the eyes of the sociologist rests firmly placed on the external, Durkheim then coins his "first and most basic" methodological "rule": the imperative that "social facts" should be "considered [...] as things" ([1895] 2013b, p. 29). Again, this is meant purely methodologically. The social is to be investigated on the basis of a scientific attitude as something external to the individual and psychological through, for example, statistical facts (as in Suicide) or the coming into being of certain (observable) juridical institutions (as in Division). Again, however, the psychological asserts itself, and again the social ends up being paradigmatically defined in terms of experience of coercion. Then, the thing-metaphor does not merely denote something external but rather a certain (selective) form of experience of physical things, more precisely an engagement with the external world in terms of resistant and impenetrable opposition:

A thing is principally recognizable by virtue of not being capable of modification through a mere act of will. [...] We have seen that social facts possess this property of resistance. Far

4 Also Suicide, supposed to carry out the methodological program of Rules (see [1897] cf. 2002a, p. xxxvi), contains ample psychological "speculation", not least, of course, in the construction of the three "ideal types" of suicide (cf. Cuin, 2000). 
from being a product of our will, they determine it from without. They are like moulds into which we are forced to cast our actions. This necessity is often ineluctable. Yet even when we succeed in triumphing, the opposition we have encountered suffices to alert us that we are faced with something independent of ourselves. Thus in considering facts as things, we shall be merely conforming to their nature ([1895] 2013b, p. 37).

Coercion is the very "nature" of the social. It is hard not to see an implied ontology here. As has been remarked by interpreters from different backgrounds, but equally critical to the Durkheimian tradition (cf. most radically Adorno, 1979; Latour, 2014), Durkheim's sociology is not bereft of a certain totalitarian attitude. We now see, in fact, how this attitude follows from the programmatic point of departure. Durkheim's understanding of the social in terms of authoritative norms (backed by sanctions) follows directly from his programmatic wish to demarcate the social fact. Durkheim then uses the metaphor of the thing to describe the action of social norms. The violent opposition between the individual and the social literally "reifies" the social, turns it into a question of "hard" repression or, at the very least, opposition, and this is not without consequences.

Even though Durkheim insists that the social "acts" upon us, the metaphor of the thing reduces this dimension to a question of mere hindrance or blockage. We may run the head against its hardened surface or occasionally even break through it, yet the social remains in the role of mere opposition. At this point traditional dichotomies assert themselves. Durkheim pits the principle of freedom, the "will", against external "determination", "inside" against "outside". The metaphor of the thing parallelizes the dichotomy of the mental versus the physical with the sociological dichotomy of actor versus structure. One cannot overestimate the ontological consequences of these metaphysical constructions.

The main consequence is that the social remains opposed to us. We may "triumph", assert ourselves against it, yet we are not allowed to unite with it or become part of it. The social and the individual cannot overlap. But something also happens to the social itself: it becomes decisively decollectivized or depopulated. Opposite the individual is an abstract structure of norms, a "society" which does not contain any real people, but is reduced to hindrances or blockages of isolated individuals. These individuals, on the other hand, are essentially understood as "free" in the sense of being self-contained and isolated principles of their own agency, it is only that they are forced by the external "moulds into which they are forced to cast their action" to limit themselves - like when a road is surrounded by high walls on both sides which hinder the traveler in diverging from it even though she wants to. The individuals do not meet, let alone merge and entrain. To this should be added that the very idea of reducing the social to normative authority de facto reduces solidarity to a question of fear. Society holds together because 
the individuals fear being different - not because they wish to share, to become involved, to enjoy the social or to become the same. ${ }^{5}$

Now, to be fair to Durkheim's program in The Rules, it must be admitted that he explicitly concedes that not all engagement with the social is equally coercive. He lessens the sense of constraint in two ways.

First, as already intimated, social norms are often internalized through upbringing and education and transformed into transparent habits and traditions ([1895] 2013b, p. 23). This means that "our sentiments" largely "conform" to the norms surrounding us and, consequently, that we do not feel the limitations placed upon us ([1895] 2013b, p. 20). Yet, the idea of internalization merely places the normative structure inside the individuals, it does nothing to stop their isolation. In fact, it rather enhances it. At any rate, it is only because of the reduction of the social to an overarching structure of norms, that it can be placed inside the individual in the first place. Essentially, we are dealing with an explanation of the "conformism" of solitary individuals. Polemically, lessening of the opposition between the social and the individual through internalization may make the individuals "more social" - but it makes them decisively "less collective".

More important and more interesting is, secondly, Durkheim's admission that not all social facts are equally solid or stable (cf. [1895] 2013b, pp. 22-26). Long standing norms and traditions -some "externalized" in written form, some even backed up by sanctions and institutions, others for instance "objectified" in architecture- are the most "crystalized". These are the coercive and thing-like instances of the social analyzed above. However, other social facts are more fluid. Durkheim mentions "movements of opinion" in regards to "religious, political, literary and artistic matters" ([1895] 2013b, p. 23); he mentions the rate of "marriage or suicide" or "higher and lower birth rates" ([1895] 2013b, p. 24). Evidently, such dynamics haunting cultural fields and everyday practices, display a more disorderly or ephemeral nature than stable social norms and rules. Nevertheless, as Durkheim points out -and intends to demonstrate in his next book, Suicide- statistical analysis of such phenomena will show that their rates or relative frequency (in respective societies) are constant (or at least continuous); a fact which, in turn, shows us that we can short-circuit the eventual individual interpretation of the phenomenon and focus on the sheer social side to it as an independent -"external"- object of study. However, it is obvious that the concept of externality here changes dramatically in comparison with the thing-like externality of the solid facts. The social loses its coercive edge. The felt opposition between the

5 The critic may reasonably object that Durkheim - as the Kantian he were- repeatedly insist that the social is not reducible to naked fear of sanctions but involve a sense of respect for the moral or normative command. This claim will be taken up in the next section. What is important here is that Durkheim -probably again inspired by Kant here- thinks of the social in terms of precepts, maxims, rules and norms 'followed' by the singular individual; a scenario which involve both coercion and de-collectivization. 
social and the individual disappears on the psychological level -often the individual does not even know that she is part of such a "social current". ${ }^{6}$ Externality is reduced to the analytical fact that a posterior statistical "dissociation" of the individual and the social is possible, showing that these collective dynamics do possess a life sui generis (transcending the meaning the singular individuals allot to them in their actions). ${ }^{7}$

The real test for Durkheim, however, is whether he can make sense of the most spontaneous and participative instance of collectivity: the crowd. This topos was extremely salient in the period. We are in the midst of the industrial revolution and the masses on the street of the fast-growing Western cities are making themselves felt with an acute -and in the upper classes disquieting- presence. Gustave Le Bon's infamous essay on the Psychologie des foules ([1895] 1905) came out the same year as Rules and also Durkheim's rival Gabriel Tarde occupied himself with these themes. Durkheim had to accomodate the crowd -and he had to do so on the basis of the principles of his new and anti-psychologistic (and anti-mimetic) sociology. In my opinion this is where he runs into real difficulties. Evidently, this time the social is not yet there, but only comes into being with the assembled individuals. But how to make sense of concepts like "spontaneity" ([1895] 2013, p. 22) and "direct corporation" ([1895] 2013, p. 25) and at the same time insist that the social is "external" to the individual? How to feel part of something that you are not part of - but explicitly separated or "dissociated" from? Isn't it simply impossible to give voice to the feeling of excitement, presence and participation belonging to being part of a crowd, if one insists upon understanding the social in terms of an "external" normative structure "imposing" itself upon the individuals "from without". Durkheim's early accounts of effervescence are strongly impressed by these ambivalences:

But there are other facts which do not present themselves in the already crystallized form but which also possess the same objectivity and ascendency over the individual. These are what are called social 'currents'. Thus in a public gathering the great waves of enthusiasm, indignation and pity that are produced, have their seat in no one individual consciousness. They come to each one of us from outside and can sweep us along in spite of ourselves. If perhaps I abandon myself to them, I may not be conscious of the pressure that they are exerting upon me, but that pressure makes itself felt immediately if I attempt to resist them.

6 This should not be misunderstood: Durkheim does not, of course, investigate Suicide in terms of imitation or collective dynamics. The paradigmatic suicide is not the sectarian one -but indeed the one committed by an isolated individual without regard to others (see esp. [1987] 2002, p. 269). The social "forces" or "causes" behind the rate of suicide must be decollectivized.

7 Add to this that Durkheim's critical choice of the case of suicide makes matters even more complex. Then, given that one of the main findings in Durkheim's study is that modern suicide results from "anomie", the notion of the social fact in Suicide ends up meaning exactly the opposite of what a social fact means in the solid case. Generalizing from the case of suicide, the "externality" of the fluid social fact amounts to an absence of norms, whereas the "externality" of the stable social fact amounts to the imperative presence of norms. At any rate, it is hard to really make sense of what "force" and "externality" means under such privative circumstances (see again [1897] 2002a, p. 269). These questions, however, are not pursued. Durkheim merely uses the same words and the same rhetoric to cover over this discontinuity. As to the many definitions of the sense of constraint, see Lukes (1973, pp. 12-14). 
[...] Now, if this external coercive power asserts itself so acutely in cases of resistance, it must be because it exists in the other instances cited above without our being conscious of it. Hence we are the victims of an illusion which leads us to believe we have ourselves produced what has been imposed upon us externally. But of the willingness with which we let ourselves be carried along disguises the pressure we have undergone, it does not eradicate it. [...] Even when we have individually and spontaneously shared in the common emotion, the impression we have experienced is utterly different from what we would have felt if we had been alone. [...] It is then we perceive that we have undergone the emotions much more than generated them ([1895] 2013a, p. 22).

Durkheim cannot allow the individuals an active role in the bringing about of the social. Rather the social descends on each of the individuals, as it were, from above. Even if such forms of "objectivity" are softer than the crystalized ones and we do not feel the same resistance and opposition, they are no less external and determining. Indeed, according to Durkheim it is mere "illusion" on the part of the members of the crowd to think that they have actually "generated" or "produced" the collective emotions they enjoy or "undergo". The active and the passive cannot overlap, and nor can the internal or the external or the individual and the social. The actual production of determination, the conflation of internality and externality finds no place in Durkheim's account. Rather he insists on observing the borders even when they are not there: he thus claims the presence of an external power even when we do not feel it. But this is simply phenomenologically wrong: when we are "willingly" "carried away" by the collective it is exactly because we do not feel the social as an "external coercive power" or "pressure". That it is possible (sometimes) for us to resist or object or refrain from participating does not mean that this "force" is always external. Most often -whether we are talking about the enjoyment of intimate social settings or concerts or festivalswe consciously produce and enjoy collectivity in the same breath, we simultaneously intensify and animate, on the one hand, and "undergo" and suffer these emotions and forces, on the other. Durkheim has no room for this simultaneity, this mixture of the individual or psychological and the social or sociological. He insists on artificial distinctions. He cannot leave the dichotomy between the internal and the external behind because his sociological program is tied to it. The result is that his descriptions violate phenomena and that he sees pressure and coercion where there is none. Again, the reader should remark how Durkheim's consistence in rhetoric - using the same expressions of "externality", "force", "pressure" and "coercion" - covers over deep ontological and phenomenological differences.

We cannot but conclude that the young Durkheim first and foremost understands the social in terms of coercion and externality - in fact he stretches these concepts beyond their breaking point. The impression that remains is the reification of the opposition between the social and the individual. The social is not simply to be "considered as a thing", but rather is like a thing. In fact, even though Durkheim repeatedly insists 
-from the "Preface to the Second Edition" of Rules ([1901] 2013b, p. 16) all the way to The elementary Forms of Religious Life ([1912] 1995, p. 214)- that the priority given to social coercion in the early work is merely "methodological" (in the sense that he emphasized this dimension because it is the most striking aspect of the social fact), this is at best to be understood as a very selective reconstruction. There can be no doubt: in Rules the social is essentially normative coercion. As Durkheim tells us: "constraint is the characteristic trait of every social fact" ([1895] 2013b, p. 97, my emphasis). As indicated, moreover, this idea can be found all along Durkheim's work (cf. Durkheim's strongly dualistic 1914 paper on the "Homo Duplex" ([1914] 2010). Evidently, it is not in such passages that we find a more collectivist picture of the social or descriptions that may do justice to the crowd.

On the other hand, we do find instances even in his early work where Durkheim contours a different relation between the individual and the social. Already at this point he has opened a small space for the existence of positive forms of "attachment" to society ([1895] 2013b, p. 98). ${ }^{8}$ The precondition, nevertheless, is highly individualistic: The individual should understand his "natural state of dependence and inferiority" vis-à-vis society, a being which is so "much richer and more complex and permanent" than his individual being ([1895] 2013b, p. 98). These ideas are further developed in the next phase of his work. In fact, already two years after the publication of Rules -and in the very book meant to carry out its sociological scientific program- the coercive dimension seems to have lost its hegemonic status. A dimension of "integration" emerges which is of equal importance to the dimension of coercion in constituting the social. This attempt by Durkheim to complement his coercive idea of the social as "regulation" with a dimension of positive "integration", is characteristic of the next phase in Durkheim's authorship.

\section{Second Phase: Integration}

The different types of suicide developed in Suicide ([1895] 2013b) are based on the above mentioned distinction between regulation and integration (to this distinction see Isambert, 2000; Steiner, 2011, pp. 42-51; and notably Besnard, 1887, pp. 48-88). Durkheim's idea is that deficits in these two aspects of the social bond then results in two different types of suicide: whereas a deficit in norms (and a corresponding lack of regulation and suppression of individual desires) as already indicated, leads to "anomic" suicide, a deficit in integration (and a corresponding lack of coherence and "attachment" to "society") leads to "egoistic" suicides.

So what is "integration"? Does Durkheim begin a much needed "re-collectivization" or "repopulation" of his idea of the social at this point? We cannot go through

8 We find such positive attachments already in Division ([1893]; see for example 2013a, pp. 81-84). 
Durkheim's two chapters on egoistic suicide here. Yet, Durkheim in fact starts out with a fairly collectivist interpretation of the concept:

For [men] cling to life more resolutely when belonging to a group they love, so as not to betray interests they put before their own. The bond that unites them with the common cause attaches them to life and the lofty goal they envisage prevents their feeling personal troubles so deeply. There is, in short, in a cohesive and animated society a constant interchange of ideas and feelings from all to each and from each to all, something like a mutual moral support, which instead of throwing the individual on his own resources, leads him to share in the collective energy and supports his own when exhausted ([1897] 2002a, p. 168).

Durkheim is close to preempting insights belonging to his late work here: The idea that the bond that unites a certain collective comes into being through a shared object or "common cause"; the idea that emphatically sharing "charges" what is shared and thus "attaches" the group to it and to each other at one and the same time. Indeed, through "uniting" with others, we "attach [...] to life".

Yet, Durkheim does not go that far. First of all, as a close reading of the chapters on "egoistic suicide" will make clear, Durkheim again and again conflates the two aspects to the social; the dimension of regulation and discipline constantly threatens to colonize the dimension of integration (cf. Isambert [2000, pp. 102-104], on a more general level Riley [2012]).

It seems that Durkheim's very conception of the social contains an inherent bias in favor of the repressive dimension to the social and its limiting function in relation to the desires of the individual. ${ }^{9}$ Indeed, in Suicide Durkheim has acute difficulties of conceiving of a positive -or simply non-coercive- force inherent to the social itself, in the sense of a form of social bond or production of order which is not built on norm-following. Tellingly, in Durkheim's account, deficiencies in "integration" does not primarily lead to isolation or loneliness (sentiments which still bear the (negative) imprint of collectivity) but rather to forms of individual fatigue, loss of élan and depression. In the end all concrete collective facets of the concept of integration disappear. The pages concluding the chapters on "egoistic" suicide and thus Durkheim's reflection on the phenomenon of "integration" ([1897] 2002a, pp. 168-174) entail a psychologizing and metaphysical tour de force which basically takes the reader from the enumeration of different collectivistic phenomena emerging among concrete humans beings or crowds or gatherings to a completely different and normatively laden scenario where isolated individuals are meant to cultivate a veneration for "society" as such -understood as the precondition for a civilized life and for (respect for) the moral law. It goes fast:

9 This blind spot is equally found even in Durkheim's most able commentators; thus, tellingly, even the authoritative text on the distinction between integration and regulation in Suicide ([1897] 2002a) by Besnard (1987) still theorizes both dimensions in terms of "norms". 
The influence of society is what has aroused in us the sentiments of sympathy and solidarity drawing us towards others; it is society which, fashioning us in its own image, fills us with religious, political and moral beliefs that control our actions. [...]

Through the fact that these superior forms of human activity have collective origin, they have a collective purpose. As they derive from society they have reference to it; rather they are society itself incarnated and individualized in each of us. But for them to have a raison d'être in our eyes, the purpose they envisage must be one not indifferent to us. We can cling to these forms of human activity only to the degree that we cling to society itself ([1897] 2002a, p. 170).

"Sympathy and solidarity" cannot play a role in the very constitution of the social, let alone be the social. Rather, a "society" -held together by "normative beliefs" meant to "control" action- has to be in place before such sentiments can develop. Not only does the integrative side to the social remain secondary; it is not something natural, instinctual or primordial -rather, in Durkheim, pre-social nature is egositic and anti-social-but ultimately it is "sublimated" into a celebration of "society" as such among isolated individuals. Attachment to other humans is replaced by attachment to society. But at the same time "society" is abstracted into a normative structure or a cultural reservoir which has lost any sense of the experience of other human beings or actual collective experiences.

This sublimation of the concept of "integration" or social "attachment" continues to gain salience in Durkheim's work - no doubt in relation to his discovery of the centrality of religion in the mid-1890s. Thus, in the "Preface to the Second Edition" to The Rules ([1901] 2013b, pp. 6-17), he has come so far as to openly assert that the "coercive power that [he attributed to the social fact in the first edition] "equally well" can "display the opposite characteristics" ([1901] 2013b, p. 16). The later course on Moral Education ([1902-3] 2002b, pp. 54-110) and the small lecture on "The Moral Fact" ([1906] 1965a) equally seeks to account for this positive dimension of attachment as equally important to the "disciplinary" side to the social ([19023] 2002b, pp. 17-54). Does this mean that Durkheim is ready to let in a more collectivistic and less norm-focused concept of the social? The answer is negative. The actual description of the positive side does not develop a lot from Suicide to "the moral fact". Even though salient descriptions of collectivity are to be found in these texts they all end up reiterating the sublimation of the social we already saw in Suicide ([1897] 2002a, pp. 168-174).

Nevertheless, let us move a bit closer to these ideas. Our attachment to society, Durkheim explains, is first and foremost due to the fact that society is not simply outside us, weighing down upon us, but also a part of us -just as we are a part of it: 
[T]here is in us a host of states, which something other than ourselves -that is to say, societyexpresses in or through us. Such states constitute society itself, living and acting in us. Certainly, society is greater than, and goes beyond, us, for it is infinitely more vast than our individual being; but at the same time it enters into every part of us. We are fused with it. Just as our physical organism gets its nourishment outside itself, so our mental organism feeds itself on ideas, sentiments, and practices that come to us from society ([1902-3] 2002b, p. 71).

Durkheim essentially sees society as a form of cultural and moral container of "ideas, sentiments and practices" in which we all take part and which, conversely, owns a part of us. Yet this "taking part" is not understood, so much as is clear, in terms of active participation; rather we are dealing with passive "having access to" a "reservoir" of everything which is merely common to us. Neither is it collective in the sense of something we, wittingly or unwittingly, mediated or unmediated, actively cultivate together in concrete acts of emphatic sharing. Again, tellingly, society is indeed "living and acting in" each individual (my emphasis), i.e. inside each of us taken separately. It is not to be found between or among us. Even though Durkheim seems to insist on the collective nature of the moral bond, the perspective remains paradoxically individualistic:

Society is the producer and repository of all the riches of civilization, without which man would fall to the level of animals. We must then be receptive to its influence, rather than turning back jealously upon ourselves to protect our autonomy. ([1902-3] 2002b, p. 72).

[I]s not civilized man a person in greater measure than the primitive; the adult, than the child? Morality in drawing us outside ourselves, and thrusting us into the nourishing milieu of society, puts us precisely in the position of developing our personalities. Someone who does not live exclusively of, and for, himself, who offers and gives himself, who merges with environing world and allows it to permeate his life - such a person certainly lives a richer and more vigorous life than the solitary egoist who bottles himself up and alienates himself from men and things ([1902-3] 2002b, p. 73).

I shall leave it to the reader to decide whether -or in what sense- the "person" mentioned by Durkheim here, for all her intellectual development and her access to the "repository" of the "riches of civilization", is really less "egoistic" or "solitary" than the child or the primitive? In such descriptions, obviously, becoming a social person only entails bonds to other persons in a very indirect sense.

This critique may not seem entirely fair. In fact, elaborating on his position, Durkheim explicitly insists that pure universalism - "mankind as source and object of morality"- suffers the "deficiency" that there is "no constituted society" on the universal level. He also breaks up the container image of "society" by insisting on a pluralism of scales and more concrete group "attachments":

Since, in fact, man is complete only as he belongs to several societies, morality itself is complete only to the extent that we feel identified with those different groups in which we are involved - family, union, business, club, political party, country, humanity. Invariably, 
however, these groups do not have an equal moral significance, and they perform functions by no means equally important in the collective life. [...] There is one association that among all the others enjoy a genuine pre-eminence and represents the end, per excellence, of moral conduct. This is the political society, i.e. the nation [...] ([1902-3] 2002b, p. 80).

Yet, even the smallest group must be de-psychologized and decollectivized: a "society" - no matter what size- remains a "social organism having its own consciousness, its own individuality and its own organization" ([1902-3] 2002b, p. 76). Moreover, the reader should notice that these groups - "family, union, business, club, political party, country, humanity"- seem to owe their "importance" to the "function" they fulfill in "collective life". Polemically speaking, even when he writes about "identification" or attachment, Durkheim lists only collectives which are important for "society" -functionally important, that is- and thus disregards the vast multitude of concrete and more or less ephemeral collective contexts that we actually form..$^{10}$

To sum up, Durkheim's interest in positive "attachment" or the "integrative" side to the social does not bring us closer to any admission of collectivity into his work. Concrete participation in and production of the social cannot be allowed. At its worst, it seems that the positive sense of the social merely consists in celebrating the very fact of coerciveness and discipline. The following quote is from the second preface to The Rules:

The coercive power that we contribute to the social fact represents so small a part of its totality that it can equally well display the opposite characteristics. For, while institutions bear down upon us, we nevertheless cling to them; they impose obligations upon us, and yet we love them; they place constrain upon us find satisfaction in the way they function, and in that very constraint. This antithesis is one that moralists have often pointed out as existing between the two notions of duty and the good ([1901] 2013b, p. 47).

Durkheim's claim that the social may equally well "display" the "characteristics" of "love" than of "coercion" can hardly be taken at face value - what he means is something completely different. In reality, the quote is about a tainted "love" for (social) "coercion". One understands why such passages rub salt in the critical sociologist's wounds.

For us it suffices to ascertain that such passages de facto reduce the social to its normative side. When Durkheim is at his most disciplinary, the positive and integrative side to the social simply disappears altogether -there are only norms- or is reduced to a meditation on this fact. There is no equal or merely dual relation between "duty

10 Nevertheless, Durkheim's preference for the national "group" indeed contain collective and participative aspects - so much becomes clear at the beginning of the First World War. Otherwise, Durkheim engages the national in a kind of universalist or cosmopolitical perspective. Each national state, he emphasizes, is to be seen "as one of many agencies that must collaborate for the progressive realization of the conception of mankind" (2002b, p. 79). 
and the good" here. At any rate, it remains difficult to make sense of what is really to be understood under a concept of "integration" or "attachment to society" which contains no concrete enactment (and enjoyment) of collectivity.

Yet this is not entirely true. Again, Durkheim has difficulties with the phenomenon of the crowd. This time however, the strategy is different. In fact, there is no doubt that the crowds of Suicide seems more collectivist than the example from Rules analyzed above:

Let us analyze the phenomenon. A number of men in assembly are similarly affected by the same occurrence and perceive this at least partial unanimity by the identical signs through which each individual feeling is expressed. What happens then? Each one imperfectly imagines the state of those around him. Images expressing the various manifestations, with their different shades, from all parts of the crowd, are formed in the minds of all. Nothing to be called imitation has thus far occurred; there have been merely perceptible impressions, then sensations wholly identical with those produced in us by external bodies. (1966, pp 125-126).

At the outset, Durkheim seems to tone down his insistence on externality. There is no abstract "force" rising above the heads of the individuals, affecting each of them singularly, or "causing" them to synchronize, as it were, from without. The quote does convey a sense of resonance among concrete individuals in as much as they all, Durkheim tells us, see or "imagine" the agitation of the others. Nevertheless, still, these individuals remain strangely inactive. They may "imagine" something about the emotional state of the other, but they do not actually $d o$ anything. They are not really coproducing collectivity or animating each other; they are not entraining or engrossing.

The dismissal of the concept of "imitation" at this particular instance -we are dealing with a rejoinder in Durkheim's debate with Gabriel Tarde- simply means that, according to Durkheim, "robotic" imitation-Durkheim thinks about unconscious and unidirectional "rays" of suggestion- cannot account for the production of collective energies. Only much later, when Durkheim engages with actual ethnographic empirical material on ritual (and the role of imitation in ritual) will he be forced to reconsider and enrich his idea of imitation -making it reciprocal and engrossing as well as active and passive, internal and external. This is not possible for the Durkheim of 1897. Arguing that these processes are felt in ways "wholly identical with those coming to us from external bodies" he falls back into his claim to an absolute dissociation of the social and the individual and thus to a complete exteriorization of the social.

\section{Third Phase: Collectivity and objectivity}

There is in fact a question in Durkheim that we have not yet investigated: Where does the special sense of obligation or authority come from, with which moral rules 
are invested, and in which their "constraining" character originates. Durkheim does not tell us much about this in Division or Rules. At this point, it seems, he simply thinks that certain collective representations or beliefs -by their sheer fact of being collective- gain a phenomenological surplus of intensity or "prestige". There is no doubt either that Durkheim in his later work complimented these constraining norms with positive "ideals" symbolizing attachment and integration in the individualized and sublimated sense given to these words above. Undoubtedly, this second development is propelled by Durkheim's discovery of the sociology of religion in the mid-90s. What characterizes the third stage in Durkheim's work, however, is two further developments. The first is an enlargement, way beyond the religious sphere, of the very scope of objects subject to (positive or negative) projection; an enlargement which also implies an extension of the range of possible phenomenological powers, intensities or fascinations of these objects. The second is a concrete investigation into the mechanisms of projection. This is Durkheim's discovery of religious ritual. In a nutshell, as long as Durkheim has not concretely situated the actual production of collective emotions, the mechanism of projection remains elusive. Durkheim's idea of a "cult of man" illustrates this point.

Durkheim's reflections on the alleged universality of modern morals contain at least one possible point of connection to concrete collective energies and concrete attachments; a point where his thought -at least to a certain degree- detaches itself from the idea of society as a pre-existing "external" container forming and shaping the cognitive, moral and social life of isolated individuals so as to make room for descriptions of actual co-production of collective ties. This is the "cult of man". ${ }^{11}$ This is one of the central instances in Durkheim's early thinking centered on the actual consecration of on object in a participatory and yet decisively modern context. Tellingly, even though we are dealing with a topos, the history of which stretches across Durkheim's entire work, the figure of the "cult of man" is rarely found in the context of Durkheim's reflections on "attachments" or "integration". We cannot here go into detail with the development of this idea in Durkheim, yet, obviously, the notion of the cult implies - potentially at least - a more active and contextual form of sharing than merely having something in common. This is the decisive step from the neo-Kantian framework into an ethnographic one. Already in Division Durkheim talks about a concrete "rallying point for so many minds" ([1893] 2013a, p. 312); yet it is only in The elementary Forms ([1912] 1995) that this cult really becomes something the individual does not merely suffer, but also actively participates in.

11 Another example of a charged object which likewise is to be found across Durkheim's work is the charismatic leader; again it is significant how the earliest examples (see for instance [1993] 2013a, pp. 152-153; [1895] 2013b, p. 99) emphasize the leader's "authority" (instrumental in "commanding" merely passive subjects), while the late examples (see notably [1912] 1995, p. 212) focus on actual production of collective energies, positive attachments and spontaneous dynamics of projection: "opinion" can be "infatuated" with "a man" ([1912] 1995, p. 215). 
It is only in The Elementary Forms that the relation between the collective and the objective really gains contour -even though, as we will see, it is never sufficiently elaborated on the theoretical level:

It is by shouting the same cry, saying the same words, and performing the same action in regard to the same object that [the Australians] arrive at and experience agreement [...].

The individual minds can meet and commune only if they come outside themselves, but they can do this only by the means of movement. It is the homogeneity of these movements that makes the group aware of itself, and that, in consequence, makes it be ([1912] 1995, p. 232).

There can be no doubt: the account of ritual given in The Forms includes entrainment and imitation as central ingredients (cf. also [1912] 1995, p. 218, 220). This is what engenders the collective emotions in the first place. Yet this time entering positively, imitation is not the mere "automatic" and passive form, Durkheim rallied against in Suicide ([1897: 2002a, pp. 74-82; on Durkheim and imitation see also Schiermer [2019]). The individuals here actively produce the sentiments which will overtake them; there is no sharp distinction between internality and externality. The "coercive" forms or "movements" spontaneously "crystalize"; "homogeneity" merely emerges on its own accord, as it were, inseparable from the sense of positive attachment and enjoyment of participation. There is no experience of external "imposition" to be found here, nor are there any "individuals" present whose desires or aspirations must be curbed and disciplined. Rather these desires and aspirations emerge out of the collective situation without any sense of imposition or coercion -and even with some room for individual expression. Making room for collectivity implies a rupture with the actor-structure or individual-society dichotomy. You cannot have both at the same time. In the late work the crowd moves to the centre- and the early idea of an abstract and stable system of norms and rules loses its paradigmatic status.

Durkheim's early account of the phenomenon of fashion is instructive as a form of contrastive folio in understanding this displacement. The following remark is found in Rules:

If purely moral rules are at stake, the public conscience restricts any act which infringes them by the surveillance it exercises over the conduct of its citizens and by the special punishment it has as its disposal. In other cases the constraint is less violent; nevertheless it does not seize to exist. If I do not conform to ordinary conventions, if in my mode of dress I pay no head to what is customary in my country and my social class, the laughter I provoke, the social distance at which I am kept, produce, although in a more mitigated form, the same results as a real penalty ([1895] 2013b, p. 21).

This coercive account, however, is simply not sufficient for explaining why we choose the clothing items we do. Granted, there are clothing conventions the breaching of which would lead to me being isolated, ridiculed or "laughed" at. In certain situations 
-funerals, formal dinners, business etc.- I may dress differently than I actually like to out of respect or simply not to stick out. Yet, there are also clothing fashions (in the narrow sense of the word), the following of which is not reducible to mere conformism. In fact, we follow fashion, not because we do not want to stand out, but because we do (cf. Simmel, 1997). The follower of fashion is seduced by the (collectively produced) luster of the fashionable object and hopes to stand out positively on this basis. In other words: fashion is not about norms but about objects; not about coercion but about positive "attachment", not about fear of being different (or of respect for "authoritative" rules) but about wanting to be the same. There is no need for potential sanctions. The "norm" in question -the appropriation of the same commodity, clothing item or object as other individuals - is inseparable from the effervescent and imitational appreciation and construction of its attraction. When we participate in something the normative and the integrative, the coercive and the regulative dimension coalesce.

These examples combine collectivity and objectivity: On the one hand, collective energies -"experience of agreement", tightening of social bonds- are enforced through imitation, mutual tuning-in, entrainment, emphatic sharing. On the other hand, everything revolves around an object upon which these energies are projected. The imitational tightening of the common bond passes through an animation of what "it is all about", what is shared, the object around which the imitational processes occur (cf. Collins, 2004, 47-101 [Ch. 2]).

As is evident, we are dealing with a generalization of the sacred. In the late Durkheim quasi-sacred objects proliferate: "postage stamps" "pearls", "diamonds", "furs" and "laces", "articles of dress", "luxury", the "caprices of fashion" are placed on the same level as the national "flag", "blood", the "cult of man", religious "idols". The sacredness of a totem of a clan is seen as an expression of the same basic projective dynamic as the attribution of "value" to commodities or money (cf. [1912] 1995, p. 228-229; [1911] 1965b). The "authority", the prestige or charisma -the sheer "psychic energy" or "intensity" ([1912] 1995, p. 209)- radiating from popular cultural, political or religious "leaders" ([1912] 1995, p. 209) -is yet another recurrent theme in Durkheim when it comes to the modern sacred. In short:

There is no active faith, how secular it may be, that has not its fetishes [...] ([1911] 1965b, p. 87).

Or in even more generalized terms: There is no collective without its quasi-sacred object. All "actual" collectivity comes into being through the "active" charging of an object. What Durkheim writes about the Australian aboriginals, he could just as well have written about modern society:

Never perhaps, has divinity been closer to man than at this moment in history, when it is present in the things that inhabit his immediate surroundings and, in part, is immanent in man himself. In sum, joyful confidence, rather than terror or constraint, is at the root of totemism ([1912] 1995, p. 225). 
As is tangible for anyone who opens a fashion or lifestyle magazine, goes to a museum, participates in heated ideological discussion -in short: cultivates shared fascinations, emotions or opinions of whatever kind- there is no reason to think that the sacred has been expelled from the "things" that "inhabit the immediate surroundings of man".

Finally, once we have left behind the mere contemplative and individualized hypostatization of "society" as a sacred object "set apart", we can also leave the container image behind with its concomitant ideas of "society" as a benevolent "mother" or a cultural "enrichment" exclusively covered with positive connotations. ${ }^{12}$ From now on, the nature of the sacred object exclusively depends upon the emotions projected upon it, and these emotions can be good or bad, full of love or desire or of fear or hatred-depending on whether we are consecrating a loving God, an attractive object of fashion, a democratic constitution or instigating a witch hunt or collectively constructing a shared enemy. Unfortunately, the enjoyment of these emotions, the energies released when these objects are animated and amplified collectively, are themselves beyond good and evil.

The explanatory power of this collectivist template of projection extrapolated from Durkheim's late work can hardly be overestimated. What Durkheim tells us is essentially that the social revolves around breathing life, fascination, importance, sensuous attraction, presence and actuality into emphatically shared objects. This goes on in the most intimate settings and it goes on in extended, mediated and anonymous collectives. All the time we animate social ties by animating what we talk about or do together - and all the time we animate what we talk about or do by animating social ties. What we emphatically share, what we center on together with others, enhances its powers and its hold upon us, increases its forces and its agency. ${ }^{13}$ This happens around shopping windows, at scientific conferences or around the family table, in blog threads and fora on the internet, just as it happens to themes on the media agenda and in relation to all significant collective "events". Just like a dance gain control over the dancing couple who cultivate the "objective" contours or movements internal to this collective practice together, so an ongoing and focused discussion gains further

12 For a critique of Durkheim's quasi-religious relation to "society" see again the critique in Adorno (1979) or in Latour (2014) -but see also the more loyal critique of Pickering (1984, p. 244). Durkheim is of course well aware, on the other hand, that the crowd is in no way necessarily a loving creature (cf. for instance [1895] 2013b, p. 22; [1912] 1995, p. 213). Yet, he never explains why the crowd may be ambivalent while society remains exclusively benevolent. However, part of the answer is that he has turned society into a sacred object by de-collectivizing it, detaching it from the crowd; of course, he cannot do the same thing to the crowd itself.

13 This dialectical reinforcement is also tangible in Durkheim's "sacred mission" (Riley, 2012) of founding and keeping afloat the Année sociologique. Doing something with others simply makes it more interesting (this relation between "integration" and personal motivation or energy is also documented in Suicide which is exactly from this period). Collectivity creates attachment to the shared object; it agitates and animates it. As Durkheim gratefully writes one of his younger collaborators, who he had been afraid to loose: "to remain attached to [the shared labour myself]", "I needed, to feel your attachment to it" (cited from Riley, 2012, p. 187). 
contour, power and importance when the participant discussants become even more engaged, so the fashionable object further increases its aesthetical allure and its enigmatic attraction by being ardently desired together with others. The collective and the objective interweave.

Before concluding, and in the hope of further contouring my reading of Durkheim, I shall briefly compare my ideas - especially my distinct focus on the dialectical and projective relation between collectivity and objectivity - with two topical and imaginative readings of the late Durkheim. I am thinking of Jeffrey Alexander and colleagues' so-called "strong Program" (Alexander \& Smith, 2006) and Randall Collins idea of Interaction Ritual Chains (Collins, 2004).

\section{The Strong Program and Interaction Ritual}

The late Durkheim plays a prominent role in both the "Strong Program" and in Collins' work. Just as I do in this paper, and for all their differences, the two "schools" equally highlight the timelessness of the late Durkheim's insights. They are both informed by Durkheim's concept of the sacred and the possibility of extending (the applicability of) this concept beyond the religious sphere. In this section, I will briefly situate my own 'collectivist' reading of Durkheim in relation to these two positions.

Now, whereas I tend to agree with the critique directed against Collins for remaining too focused on the interactionist level (Cf. Smith, 2012), I agree to Collins' placement of the dynamic of collective projection -the relation of enforcement between collective sentiment and shared object or focus- at the absolute center of sociological analysis (Collins, 2004, pp. 47-101). In my view, we find no comparable dialectics in the Strong Program. The latter instead emphasizes the importance and (relative) "autonomy" of culture as the point of departure and distances itself from Collins' point of departure in ritual (cf. Smith, 2012; Smith \& Alexander, 2008). There is, however, a danger that this dichotomous framing pits ritual against myth -collectivity against culture- in ways that hinder the study of the dialectical interplay and dynamic of reinforcement between the two dimensions -indeed the exact relation between collectivity and objectivity which interests me in late Durkheim.

Let me give you some illustrations of this blind spot in the Strong Program. Alexander's meticulous analysis of Watergate is a good place to start. Here he applies the dichotomy between the good or evil sacred to analyze the dislocations in status or popularity of Nixon as the events unfold and the eventual recharging of universalist and republic values and important democratic institutions after the crises; he underlines the psychological and emotional effects of these dislocations (and criticizes structuralism for ignoring them); he spells out the details surrounding the televised Senate hearings in the Summer 1973, which were, no doubt, to have 
enormous influence in creating a "ritual communitas for Americans to share" (1988, p. 200). However, such formulations should not lead the reader to believe that Alexander is interested in the collective level in its own right, let alone that he is ready to allow it a proper role in the analysis. The movement is only one-way. There are collective emotions to be found in Alexander, there may even be real gatherings or rituals, yet they do not, it seems, help to blow life and importance into these values and institutions from below. We find no descriptions in Alexander as to how the "Americans" actually participate (in any active sense of the word) in rejuvenating -sacralizing- these objects.

Or take another example: Alexander's meticulous analysis of the construction and generalization of the Holocaust as the paradigmatic example of absolute evil (2006, pp. 27-84). On the one hand, again, Alexander's analysis demonstrates that cultural "form" matters. Undoubtedly, the genre of tragedy, the dramatization of trauma, the uses (and dislocations) of prominent dualisms help to structure the material; once more, moreover, Alexander has a keen eye for the role of media and television in mediating and "personalizing" the terrible event; he even touches upon the dimension of monuments and museums and processes of collective remembrance.

Nevertheless, in my view, it still feels like Alexander's analysis only gives us half of what really happens. At best there is an "audience" to the "performance" or the "(trauma) drama", yet, as is clear, this audience remains strangely metaphorical, it does not make a difference; -as if a performance is really a performance without the energetic ambience created by (the sheer presence of) a real audience. Likewise, isn't the dynamic of "catharsis" -and, in fact, already in Aristotle- further enforced by its collective context (actually taking place in the Amphitheatre)? Don't the visitors to the Jewish museum in Berlin enact the architecture together to make the most of it all? Isn't the identification with Anne Frank cultivated in concrete school classes and friendships among American teenagers (are there no actual collective aspects to the enactment of rituals around her)? Isn't, ultimately, the sheer psychological need to tell the story, to enforce the numbers, to recall the magnitude, reanimate the atrocities, to enter into the "spiral of signification" (Alexander, 2006, p. 93) -that is, to cultivate and expand myth- isn't all this -at least also- an effect of actual collective energies, of concrete human beings wanting to entrain and actively enact the social (around the impure object). And the other way around: Isn't even the imposition to refrain from myth a negative rite? Isn't the very insistence on the non-representational or ineffable nature of the holocaust event among historians, writers and philosophers also a way to transmit the sheer fascination of a(n impure) sacred object, a form of enactment of collective emotions through taboo, reinforcing effervescent animation by insisting that the events cannot be told, cannot be done justice, that this is a profanation, that they must be held apart, that they are dangerous 
and contagious ("it can happen again!"), -indeed there are rituals to observe and we ought all to do so. At any event, such taboos do not merely result from the sacred, but also help to create and enliven it.

Well, Alexander's insistence upon the "analytical autonomy" of culture (2015, p. 2) obfuscates exactly the possibility of focusing on the dialectical interplay -or intraplay- of collectivity and culture. Unfortunately, to avoid making a "naturalistic fallacy" (2006, pp. 27-33, 91-93), Alexander ends up doing a culturalist shortening. Instead, we need to mix Collins and Alexander; find out how the cultural forms, Alexander has such a keen eye for, not only helps to create collective resonance, but also accommodates, transforms and channels it into discourse, making myth reverberate and expand, -in turn, further animating the collective. Whether such a dynamic of dialectical reinforcement actually takes place and how intense it becomes is of course an empirical question.

What is important analytically is, however, to remind the Strong Programmers of the fact that, without the collective, nothing happens. Also the collective side must be granted some autonomy. Then, ultimately, the collective decides for itself: sometimes the party just doesn't "happen", the applause dies half-way, a planned fashion or invention flops, a mass ritual or concert fails, the planned hearing fails to arouse the audience -and thus simply loses importance and impact. Now, to be sure, this dynamic may be catered for, manipulated, provoked through all kinds of means- notably, of course, through all kinds of staging and aestheticization of the sacred object, through synchronization through music, through excessive circulation, engagement of important critics or gatekeepers, through use of other sacred objects which may rub off on it, through taboos and forced rituals -and yet, ultimately, collective entrainment can neither be mastered nor produced on command. To answer Alexander's question polemically: "who controls the means of symbolic production?" the answer is ultimately: the collective. In the last instance it is the collective who creates the sacred. It is the collective that bestows it with its surplus energy, its force of fascination, its importance, its "super sensuous" attraction, its inviolability, that is with a special appearance or "surface", as Alexander wants it, that transcends all deliberate aesthetizisation. ${ }^{14}$

This is indeed where Alexander's recent "iconic turn" comes into the picture. With this reorientation Alexander not only seeks to do justice to the phenomenological

14 Granted, Alexander does elsewhere emphasize the lack of power of the "producers" to "ensure and control audience reaction" (2015, pp. 4-5). However, merely conceding that the "aesthetic effectiveness of the icon remains unpredictable" since there is a "long way" "from icon to audience", does not entail thinking of the collective at the very least as "co-producer". Alexander's collective remains in the role of a passive or merely "re-active" "audience". Instead of, as Durkheim, to insist on the actual collective forces as the creators of the "delirium" of experience (esp. Durkheim, 1995, pp. 224-231), Alexander's icons seem to exist apart from the collectives needed to enliven them. Alexander does not seem to want to admit that the sacred -the fashionable commodity- needs to be "produced" at least partly by the consumers it wants to seduce. 
surplus of the sacred and its ineffable and quasi-sensuous power of fascination. The new-found interest in the sensuous and aesthetic, moreover, has also allowed him to progressively extend the sacred (even further) beyond the political and moral areas focus his earlier work (and of Bellah's civic religion legacy). Alexander's work on celebrities and other popular icons (Alexander, 2008, 2010) shows his willingness to expand the scope of analysis beyond Durkheim's insistence on la vie serieuse and to do justice to the phenomenological intricacies of popular culture. This step can only be welcomed. The privileging of the political and moral over the cultural (in the narrow sense) is indeed a Durkheimian vice that should have been redirected long ago. ${ }^{15}$

Nevertheless, once more Alexanders' fear that the sui generis life of culture should somehow be reduced to the social instead leads him to reduce the social to the cultural. Alexander insists his icons are "social objects", yet they are so only in the sense that they "socialize" with the individual; that the intense relation between the subject and the iconic object is of central importance to the individual in question. Alexander does not refrain from calling upon Durkheim's notion of the social fact (2010, p. 332), yet how this "social" relation between the subjective and the objective is itself coanimated and co-agitated by collective energies is left out of the analysis. To be sure, Alexander has a keen eye for the fact that "sensuous qualities" or "aesthetics" may "command attention", "compel attachment", "trigger absorption" and fascination (2010, p. 324), yet he has little sensibility for the fact that it is also the sheer popularity or collective resonance of the object that creates its "sensuous qualities" and thus, consequently, also enforces its "depth". Then, the "depth" dimension to the object -the intellectual or cognitive expansion of its meaning, i.e. the dimension of myth or culture- is, as Alexander clearly sees, triggered by the ineffable aesthetic powers of the object's "surface", provoking the desire to convey and further enhance its beauty, rationalize its powers and its hold upon us. ${ }^{16}$ Take Alexander's listing of enthusiastic celebrations of Givenchy's (version of the) famous "Little black dress" (originally created by Chanel) worn by Audrey Hepburn in the 1961 film "Breakfast at Tiffany's":

The front severe, elegant, very clean, but at the back this very interesting neckline, somewhere between ethnic and Parisian; a softness that other designers in that time did not have (Riccardo Tisci (Givenchy) as cited in Alexander, 2010, p. 328).

Givenchy's dresses complemented that in spite of their simplicity. It shows confidence to

15 Durkheim insistence on the stable and enduring goes hand in hand with his mistrust of modern culture. In his eyes, the strong yet ephemeral and shifting collective formations, the volatile sharing of collective energies and objects found in cultural contexts - in the arts, in science, in fashion, in the entertainment industry, in modern commodity culture - merely qualify as forms of "malign" or "morbid" effervescence (see notably 2002a, pp. 328-351; [1993] 2013a, pp. 8-32; cf. Riley, 2012, p. 182). Apparently, it is only in political or religious contexts that effervescence has an integrating effect.

16 On the formal level, these mechanisms are no different from the impure case -Holocaust- touched upon above. 
wear such simply graceful dress that is not calling attention to itself. Not showy, not flashy, just confidence that the woman herself will attract the gaze (Actress Natalie Portman as cited in Alexander, 2010, p. 328).

Such "accounts" present a form of cultural rationalization of a phenomenological surplus which, in turn, results from the projection of collective energies originating in a concrete (albeit largely mediated) cult. In a word: The attractions of the fashionable object, in reality the effect of a projection of collective energies upon the object, are ascribed to the object itself (or to its creator). Yet this rationalization also further animates the object, and this animation happens, obviously, via cultural and moral commonplaces, (gendered) binaries and values and authenticities with their own structuring affect. Ultimately, what takes place here is also a ritual act, helping to prolong and reanimate the cult around the sacred classic. But is it only a ritual act? Do we have to be reductionist? Do we have to follow Durkheim in his insistence that "any object could have played this role"? (1995, p. 230), that its inherent aesthetic properties do not mean anything. No we do not. But neither should we believe, along with Alexander, that the aesthetic qualities of the icon and the binaries and schemas which structure culture are enough to create the sacred and gather the crowd.

\section{Conclusion - and a Word of Caution}

Admittedly, my reading of Durkheim and my interest in the interplay between the collective and the objective as pictured in late Durkheim goes together with a certain "selectivity" on my part. I have criticized or downplayed a number of contrary impulses; aspects which in my view point back towards the early work and the programmatic and problematic - idea of the "externality" the social, but which Durkheim in no way would renounce upon. To be sure, taking the theoretical and empirical consequences of the collectivism of the late Durkheim seriously leads to controversial positions - at odds, in fact, with some of Durkheim's most central tenets, notably his over-blown holism, his (concomitant) fascination with the disciplining and chastening side to the social (so tangible in the first phase) and his later sublimation of real collectivity (so tangible in the second phase). In my view, of course, it is Durkheim himself, who, blinded by inveterate theoretical and metaphysical presuppositions, refrains from drawing the full consequences of some of his most remarkable observations and his most brilliant phenomenological descriptions.

Durkheim never completely renounces upon the holism and the ideas of externality and coercion of the first phase nor of the idea of a form of religious relation between the individual and "society" of the second phase. Maybe this explains why, even while moving the active production of collectivity and the idea of attachment to the center, he still falls short of adequately theorizing this move. The idea of "society" as an extended and de-contextualized structure of norms and rules or as a mere container 
of cultural values and forms, in both cases seen in relation with isolated individuals, still holds sway in his thinking. The distinction between individual and society still bars him from collectivizing the individual and repopulating the social, just as it hinders him from really appreciating - even while describing it in vivid terms - the true entanglement of the effervescent and the objective.

Grant Support: The author received no financial support for this work.

\section{References}

Adorno, T. W. (1979). Einleitung zu Emile Durkheim, ,Soziologie und Philosophie‘. In Soziologische Schriften I (Gesammelten Schriften, Band 8, 1, pp. 245-279).). Frankfurt am Main: Suhrkamp Verlag.

Alexander, J. (1988). Durkheimian sociology: Cultural studies. Cambridge: Cambridge University Press.

Alexander, J. (2006). The meanings of social life: A cultural sociology. Oxford: Oxford University Press.

Alexander, J. (2008b). Iconic experience in art and life: Surface depth beginnings with Giacometti's Standing Woman. Theory, Culture \& Society, 25(5), 1-19.

Alexander, J. (2010). The celebrity-icon. Cultural Sociology, 4(3), 326-336.

Alexander, J., \& Smith, P. (2006). The strong program in cultural sociology: Elements of a structural hermeneutics. In J. Alexander (Ed.), The meanings of social life: A cultural sociology (pp. 1126). Oxford: Oxford University Press.

Besnard, P. (1987). L'anomie: Ses usages et ses fonctions dans la discipline sociologique depuis Durkheim. Paris: Presses Universitaires de France.

Collins, R. (2004). Interaction ritual chains. Princeton and Oxford: Princeton University Press.

Cuin, C.-H. (2000). Sociologie sans paroles: Durkheim et le discours des acteurs. In M. Borlandi \& M. Cherkaoui (Eds.), Le Suicide: Un siècle après Durkheim (pp. 125-146). Paris: PUF.

Durkheim, E. (1965a [1906]). The determination of the moral fact. In Sociology and philosophy (pp. 35-79). London: Cohen \& West.

Durkheim, E. (1965b [1911]). Value judgements and judgements of reality. In Sociology and philosophy (pp. 80-97). London: Cohen \& West.

Durkheim, E. (1995 [1912]). The elementary forms of religious life. New York: The Free Press.

Durkheim, E. (2002a [1897]). Suicide. New York: Routledge.

Durkheim, E. (2002b [1902-3]). Moral education. Mineola, NY: Dover Publications.

Durkheim, E. (2010 [1914]). Le Dualisme de la nature humaine et ses conditions sociales. In La science sociale et l'action (pp. 316-333). Paris: PUF.

Durkheim, E. (2013a [1893]). The division of labour in society. Basingstoke: Palgrave Macmillan.

Durkheim, E. (2013b [1895][1901]). The rules of sociological method. Basingstoke: Palgrave Macmillan.

Isambert, F.-A. (2000). Courants sociaux et loi des grandes nombres. In M. Borlandi \& M. Cherkaoui (Eds.), Le Suicide: Un siècle après Durkheim (pp. 87-108). Paris: PUF. 
Latour, B. (2014). Formes élementaires de la sociologie: Formes avancées de la théologie. Archives Des Sciences Sociales Des Religions, 167, 255-274.

Le Bon, G. (1905 [1895]). Psychologie des foules. Paris: Felix Alcan.

Lukes, S. (1973). Emile Durkheim-his life and work: A historical and intellectual biography. London: Penguin Books.

Pickering, W. S. F. (1984). Durkheim's sociology of religion. Cambridge: James Clarke \& Co Ltd.

Riley, A. (2012). Godless intellectuals? The intellectual pursuit of the sacred reinvented. New York, Oxford: Berghahn Books.

Schiermer, B. (2019). Durkheim on imitation. In C. Borch (Ed.), Imitation, contagion, suggestion: On mimesis and society (pp. 54-72). Abingdon: Routledge.

Simmel, G. (1997). The philosophy of fashion. In Simmel on Culture (pp. 187-205). London, Thousand Oakes and New Delhi: Sage.

Smith, P. (2012). Becoming iconic: The cases of Woodstock and Bayreuth. In J. Alexander, D. Bartmanski, \& B. Giesen (Eds.), Iconic power: Materiality and meaning in social life (pp. 171183). New York: Pelgrave Macmillan.

Smith, P., \& JAlexander, J. (2008). Introduction: The New Durkheim. In J. Alexander \& P. Smith (Eds.), The Cambridge companion to Durkheim (pp. 1-37). Cambridge, UK: Cambridge University Press.

Steiner, P. (2011). Durkheim and the birth of economic sociology. Princeton: Princeton University Press. 
